\title{
DESENHO INDUSTRIAL DESIGN: PROFISSÃO FECUNDA, OFÍCIO INVENTIVO, ATIVIDADE CRIATIVA
}

\author{
Luiz Vidal Gomes \\ PPDESDI-UERJ \\ luizvidalgomes@gmail.com \\ Ligia Sampaio de Medeiros \\ PPDESDI-UERJ \\ ligia@esdi.uerj.br \\ Marcos Brod Junior \\ CDI-UFSM \\ brodjr74@gmail.com
}

Resumo: O projeto de lei que dispunha sobre a regulamentação do exercício profissional de designer foi vetado em 2015. Não existe consenso na comunidade de designers sobre a conveniência dessa regulamentação, mas estudantes sentem-se, com frequência, inseguros quanto às perspectivas de sua trajetória profissional. Independentemente do contexto cultural, há consideráveis diferenças entre as práticas do design, desde aquelas mais voltadas para a arte (design autoral), até as mais orientadas para a indústria (design industrial), passando pelas atividades manuais (design artesanal). Todas essas práticas exigem muito trabalho e criatividade. Neste artigo tentaremos caracterizar o design como "profissão fecunda", "ofício inventivo" e "atividade criativa".

Palavras-chave: Profissões fecundas; ofícios inventivos, atividades criativas

\begin{abstract}
The project that claimed for the regulation of professional practice of the designer was vetoed in 2015. There is no consensus in the community of designers on the appropriateness of such regulation, but students feel often uncertain about the perspectives of their careers. Regardless of cultural background, there are considerable differences within the design of practices, from those more focused on the art (authorial design), the most industry oriented (industrial design), and the manual activities (craft design). All these practices require hard work and creativity. In this article we will try to characterize the design as "fecund profession", " inventive craft " and "creative activity".
\end{abstract}

Key words: Fecund profession; inventive craft; creative activity. 


\section{INTRODUÇÃO}

Plutão, há uma década, deixou de ser reconhecido como planeta e passou a ser denominado planeta-anão porque, com a descoberta de outros corpos similares a ele no Sistema Solar, sua classificação foi questionada. Plutão não atendia à definição formal para o termo "planeta" criada em 2006 pela União Astronômica Internacional. De acordo com a nova definição, um corpo celeste deve preencher três requisitos para ser considerado um planeta: (i) estar em órbita em torno de uma estrela; (ii) ter forma aproximadamente esférica; e (iii) ser o astro dominante na região de sua órbita.

Líderes do design brasileiro, há décadas, reivindicavam que a atividade do designer fosse regulamentada como profissão, similar àquela realizada por médicos, advogados, engenheiros. Entretanto, o projeto de lei no 24, de 2013 “que dispõe sobre a regulamentação do exercício profissional de designer" foi vetado integralmente pela presidência da república, por inconstitucionalidade (cf. Diário Oficial da União, 28/10/2015). Com o impedimento de seguir adiante com o projeto de regulamentação profissional, designers industriais misturam-se, agora, a tantos mis designers que jamais frequentaram curso (superior ou não) de formação projetual. Cursos de profissionalização perderam, assim, sua função vocacional.

Para ser regulamentado, o design precisaria se distinguir de outras ocupações similares a ele no "sistema solar das profissões". Sua classificação como profissão foi questionada por falta de uma definição formal de acordo com a qual, requisitos deveriam ser preenchidos. Quais requisitos para o design seriam equivalentes, por exemplo a "estar em órbita em torno de uma estrela", ou "ser o astro dominante na região de sua órbita"?.

Independentemente do contexto cultural, há consideráveis diferenças entre as práticas do design, desde aquelas mais voltadas para a arte (design autoral), até as mais orientadas para a indústria (design industrial), passando pelas atividades manuais (design artesanal). Todas essas práticas exigem trabalho e criatividade. Neste artigo tentaremos distinguir profissões fecundas de ofícios inventivos e de atividades criativas por intermédio das noções de trabalho projetual e de capacidade criativa.

\section{PROFISSÕES FECUNDAS, OFÍCIOS INVENTIVOS E ATIVIDADES CRIATIVAS}

A Industrial Designers Society of America (Sociedade Americana de Design Industrial), IDSA, define design Industrial como "A atividade profissional de criação e desenvolvimento de conceitos e de especificações que otimizam a função, o valor, a aparência de produtos e sistemas de produtos para o benefício mútuo do usuário e do industrialista". Esta definição é ampla o suficiente para incluir as funções dos vários membros de uma equipe que dirigem sua atenção para a configuração de um produto visando a melhor interação com o usuário, sem negligenciar as limitações da execução.

Aprende-se com Karl Ulrich e Steven Eppinger (2000) que o nascimento do design industrial, como profissão, ocorreu na Europa Ocidental nos primeiros anos do Século XX. Gui Bonsiepe - retomando seu texto preparado para a UNIDO- também ensina que "remonta ao século XIX, quando a industrialização começou a mudar a fisionomia do mundo material" (cf., BONSIEPE, 2015, p.229-250). Ulrich e Eppinger destacam que empresas germânicas de produtos maquinofaturados (e.g., AEG, indústria de produtos elétricos) comissionaram artesãos e arquitetos para desenharem produtos, a partir de tecnologias disponíveis, que auxiliassem o desenvolvimento da 
indústria alemã. À época, o valor dos desenhos (não dos projetos) marcou a cultura material de uma era e consagrou a qualidade criativa de uma nação. O impacto em termos de vendas foi percebido como consequência da combinação do desenho dos artefatos aos projetos possíveis de execução na indústria mecanizada. Além de tudo, a necessidade de se desenvolver um trabalho industrialmente sistemático resultou em duradouras teorias acadêmicas que vieram a influenciar e moldar uma profissão que, entre 1960 até 1990, era denominada no Brasil "desenho industrial".

Os primeiros preceitos de design Industrial iam além de questões técnicofuncionais, pois alteravam motes da estética artística para novos padrões da estética industrial, ao enfatizarem a importância da geometria (euclidiana/mongeana), da precisão (intercambialidade/tolerâncias geométricas), da simplicidade do desenho (síntese funcional/coerência formal) e da economia (custo de fabricação/valor do desenho) no projeto de produtos.

Resumidamente, desenhadores europeus, no início do Século XX, acreditavam que um produto industrial deveria ser projetado 'de dentro para fora'. A forma deveria seguir a função (ULRICH; EPPINGER, 2000, p.209-233).

Ainda segundo Ulrich e Eppinger, enquanto os primeiros designers europeus eram arquitetos e engenheiros, a maioria dos designers americanos eram cenógrafos e ilustradores. Não é de surpreender, portanto, que o design industrial americano estivesse a serviço do departamento de vendas e publicidade e, assim, o exterior de um produto fosse mais valorizado do que o seu interior.

A competição por posições de destaque nos mercados forçou as companhias americanas a procurarem por caminhos que melhorassem e diferenciassem seus produtos. Mais e mais projetos de produtos industriais, principalmente aqueles originados nas pranchetas dos escritórios de Henry Dreyfuss (1904-1972) e de Eliot Noyes (19101977), baseavam-se na ideia de que o desenho do produto ia além do estilo e da aparência. Para organizar esse conceito, Dreyfuss (1967) arrolou cinco principais aspectos projetuais - utilidade; aparência; manutenção; custos e comunicação- que podem atualmente ser associados a fatores - antropológico; filosófico; tecnológico; econômico e geométrico. Assim também pensamos nós: quando questões estéticoformais seguem parâmetros técnico-funcionais, percebe-se mais diretamente a lógica da informação.

São necessários cerca de 5 anos em curso universitário para um designer industrial se graduar, e esse tempo duplica no caso do designer autor: cerca de 10 anos. Se considerarmos a tese de Gladwell (2008), são necessárias 10 mil horas, cerca de 10 anos, para que alguém se destaque com presença sólida das indústrias criativas e seja bem-sucedido financeiramente com a ocupação de sua criatividade.

Tanto a educação formal do designer industrial quanto a informal do designer autor exigirão domínio de conhecimentos sobre processos de fabricação, propriedades de materiais, e técnicas de acabamentos de superfície e impressão. Em cursos de formação projetual, estudantes apreendem questões que afetam os desenhos de seus produtos; assim como habilitam-se para expressar, representar e comunicar as ideias de suas criações.

Dependendo da especialidade vocacional - desenho de ambiente; desenho de artefato; desenho de comunicação-, serão necessários cursos para treinamento 
adicional, seja no campo da arquitetura (urbanismo, interiores, comercial), das engenharias (produção, mecânica, elétrica), da comunicação (publicidade, interação, meios). Na prática de desenvolvimento de projeto de produto, designers industriais devem estar aptos também para o labor de artistas, logo habilitados para: (i) debuxarem ideias em fase de concepção; (ii) modelarem produtos; (iii) ilustrarem, valorizando gráfico-visualmente, as ideias apresentadas no desenvolvimento do processo por todos os membros da equipe de projetação.

Há tempo, ressaltamos que, mesmo usando a tão carismática palavra "design", nós, lusófonos, podemos nos adiantar aos próprios nativos de língua inglesa para compreender os sentidos do Design industrial (cf. CROSS et al, 1980, p.10). Isto não tem nada de arcaico ou ultrapassado. Veneração da palavra genérica "design" continuará dificultando a emancipação de uma profissão fecunda. Parafraseando os mestres britânicos, design é palavra com muitos significados, seu sentido varia segundo quem a emprega. Pode significar: desenho de produto - este novo modelo de placa de sinalização é um design meu; desenho de projeto -este debuxo técnico é o meu design para a sinalização do estacionamento; desenhar um processo - vou fazer um novo design para o desenvolvimento deste produto. 0 importante seria que jamais um designer industrial brasileiro dissesse isto:

In other words, to put it simply, I am not interested in design. The reason for this is that when we speak of design, we speak about objects. I am bored to hell of chairs. Even my own. One more chair, another lamp, what is the interest in that? ... We have moved from the traditional design - Bauhaus, Lowey, people fascinating by the object itself, which gave rise to some very beautiful results to the explosion... in the last 15 years, of narcissistic design, done by designers for other designers, a masturbatory exhibition of their know-how, of their panache. "Who?" Me! And everyone else! It is a type of design that cannot be innocent... Design is created exclusively by the media and for the media, photogenic objects that are media-friendly. (Entrevista de Philippe Starck a Pierre Doze, Moscou, Abril de 1996. In PHILIPPI, pp.320).

Já que designers industriais evitam o "desenho", devem encontrar o que os distingue das atividades criativas e dos ofícios inventivos no "sistema solar das profissões". Regulamentação profissional, e consequente delimitação de atuação no mercado de trabalho, somente será admitida, "quando houver a possibilidade de ocorrer dano à sociedade". Fora isso, a Constituição, em seu Art. 5o, Inciso XIII, assegura livre exercício às atividades criativas e aos ofícios inventivos.

Ainda usando a analogia astronômica, um corpo celeste importante em sua região é aquele que agregou, durante seu período de formação, a maior parte da matéria disponível ao redor, assegurando, assim, relevância na sua órbita. Designers industriais devem fortalecer sua formação com conhecimentos universitários e dominar a prática do projeto para desenho de produtos industriais visando a constituição de uma profissão fecunda, mesmo sem abdicar das oportunidades de trabalho que surgirem em ofícios inventivos ou em atividades criativas.

Profissão fecunda é aquela para a qual o indivíduo preparou-se em cursos de nível superior, academicamente, e que pretende exerce-la ao longo de sua vida adulta. Por ofício inventivo entende-se a ocupação que pode ser desempenhada por qualquer 
indivíduo antes mesmo que tenha chegado à idade adulta, exigindo-se, para isso, determinação e vocação. Os músicos exemplificam essa categoria, pois muitos tiram partido de seus ofícios desde idades bem tenras. O designer, quando em ofício inventivo, estará sempre comprometido em engendrar coisas distintas, em descobrir relações entre objetos, em proteger e guardar os produtos de sua argúcia. O designer (sem adjetivação de especialidade) como senhor de ofício inventivo, não tem necessidade realizar curso universitário, mas precisa se preparar na prática, como o fazem atores, cantores e tantos outros, para se formar classicamente para ofício inventivo de alto desempenho.

A atividade criativa é aquela na qual se aplica a intrínseca criatividade humana que permite que nos ajustemos às demandas da vida, sejam elas auto-motivadas, ou impostas por circunstâncias. A criatividade é uma função da mente, pode ser mais espontânea em uma pessoa do que em outras, e é intensificada por interações no contexto social. Designers estabelecidos em atividades criativas encontram maior oferta de trabalho, pois as demandas das indústrias criativas são mais diversificadas do que aquelas dos ofícios inventivos e das profissões fecundas.

\subsection{Design como profissão fecunda}

Como profissão fecunda, o design demanda conjunto de ações comprometidas com: (i) seriedade, que nada tem a ver com sisudez, pois demanda atender a situações de projeto de produto bem definidas; (ii) competência, que não é o mesmo que capacitação, pois, exige que o profissional possua formação para trabalho em equipes de projetação interdisciplinares; (iii) responsabilidade, algo que independentemente de idade ou do cargo funcional: indica estar preparado para assumir os riscos de fracasso e as consequências do prejuízo.

As três palavras - seriedade, competência, responsabilidade- já seriam suficientes para indicar a existência de profissão fecunda. Esta, quando liberal, é sistemática, no modo vocacional de gerenciar conhecimentos; acumulativa, na prática de coordenar e instrumentar dados; e inexaurível, no sentido de o profissional ser capaz de repetir-se, reproduzir-se, refazer-se a cada contrato de trabalho e, principalmente, diante dos reveses de carreira, causados por questões econômicas; por obstáculos empregatícios, gerados por motivos políticos; e por estorvos em ambientes de trabalho, provocados por paixões negativas como inveja, cobiça, ciúme.

O profissional fecundo, preferencialmente, realiza seus contratos em bases de pro labore, expressão latina que significa "pelo trabalho", ou melhor, "pago pelo trabalho". O aportuguesamento pró-labore significa a remuneração do trabalho realizado por sócio, gerente ou profissional liberal. Também significa o modo de se obter recursos financeiros necessários ao sustento da empresa e de seus dependentes. Quando bem-sucedido e consciente socialmente, o designer industrial - profissional fecundo- se dá o direito de destinar horas de seu trabalho para o bem da comunidade, em ações não-remuneradas, ou seja, pro bono publico, expressão latina que significa "para o bem".

Para o designer industrial, o trabalho pró-bono é apenas um outro modo de trabalho, o voluntário, mas que implica no mesmo caráter e nas devidas competências profissionais, mesmo não estando envolvida remuneração monetária. 


\subsection{Design como ofício inventivo}

O trabalho como ofício inventivo é mais amplo do que o relacionado à profissão fecunda. Isto pode ser identificado nas relações existentes entre Design \& Invention, apresentadas pela Science Reference Library London, quando, em 1989, arrolou, em programa de TV, nove passos que um inventor deve considerar para ter certo êxito em seu oficio: 1. Identifique uma necessidade; 2. Procure conhecer seu grau de originalidade; 3 . Não contradiga o que está estabelecido; 4 . Construa um modelo de trabalho; 5 . Proteja a sua invenção; 6 . Aprenda tudo sobre o sistema de patentes; 7. Seja realista sobre o custo de patentes; 8 . Venda você mesmo a sua invenção; 9. Encontre um industrialista/empresário.

Os nove passos do inventor podem aludir à sequência de fases metodológicas do projeto para desenho de produto industrial, porém, mesmo sem nos aprofundarmos nesse assunto por agora, destacamos as particularidades das formas de atuação do designer inventor e as do designer industrial no que se refere a: (i) Propriedade Intelectual: não cabe ao designer industrial, quando comissionado a desenvolver um projeto de produto, proteger legalmente os seus desenhos. Estes devem ser registrados pelo industrialista comissionador. O desenhador somente detém a propriedade intelectual quando investe em seus próprios projetos inventivos; (ii) Trabalho por Empreitada: o designer industrial trabalha, essencialmente, em regime (a) pró-labore, quando empresário de seu escritório; (b) holerite salarial, quando empregado de escritório/atelier/agência de outrem; (c) pró-bono, quando, ao atuar como trabalhador livre, dedica horas de sua labuta à comunidade; (iii) Independência Criativa: as matrizes técnicas e os matizes processuais para a formação prática no ofício inventivo podem ser alcançados pelos designers industriais de maneira assistemática, ocasional e virtual. O ofício inventivo também permite que desfrutem da sensação de independência e de liberdade da tutela empresarial e das demandas da clientela (termo, aqui usado, tanto para designar usuários que se servem individualmente de um produto, e.g., uma camisa; quanto utentes, aqueles que se utilizam coletivamente de um produto, e.g., uma ciclovia).

Esse privilégio do ofício do inventor, todavia, faz com que o designer tenha como produto de seu ofício uma "mercadoria". O pagamento pelo fruto do ofício inventivo não ocorre por contrato profissional, mas por negociação ou tabela de preços. É com base em previsão de possível sucesso do invento, que a remuneração é concordada. O acerto entre partes pode ser até bastante informal (Cf. TV Discovery Science "Batalha das Ideias"). Isto está longe do que Dorothy Goslett orientava à "Prática Profissional de Projeto", quando norteava para os contratos industriais.

Os ensinamentos de Goslett valem para designers que pretendam trabalhar tanto como profissional fecundo quanto como inventor. Em ambos os casos, é necessário demonstrar experiência com problemas da cultura material $\left(\mathbf{k}^{\text {pro }}\right)$, sólido conhecimento científico $\left(\mathbf{k}^{\text {cie }}\right)$, sabedoria derivada de experiência técnica $\left(\mathbf{k}^{\text {tec}}\right)$, prudência de circunspeção tácita $\left(\mathbf{k}^{\text {tac }}\right)$. Todos esses saberes projetuais, conhecimentos em Desenho $(\mathrm{KD})$, posicionarão inventores em vantagem para tornarem-se ricos financeiramente. $E$, mesmo que não venham a enriquecer, terão projetos de produtos para desenvolver até o fim de suas vidas. A título de curiosidade, há dois arquitetos, Frank Lloyd Wright (1867-1959) e Oscar Niemeyer (1907-2012), que podem ser tomados como exemplo do que dizemos. 


\subsection{Design como atividade criativa}

Robert Keith Sawyer, na Introdução de livro Explaining Creativity (2012), faz referência a autores que também definem criatividade. Feldman (2003), por exemplo, baseado na metáfora do teclado do piano, indica três divisões para a criatividade, a saber: "C-ALTO" (Big C), "c-baixo" (low c) e "C-Médio" (middle C). Kaufman e Beghetto (2009) propõem outro modelo fundado em dois níveis de Criatividade, dispostos em pares, com duas graduações. Atribuímos as seguintes graças para o primeiro nível: "Capital-C" e "cursivo-c". Para o segundo nível de classificação "proto-c" (mini-c), a criatividade de pessoas comuns que concebem coisas, e "profi-c" (Pro-c), a criatividade de profissionais que projetam produtos. Vale lembrar que estas metáforas nada têm a ver com melhores ou piores aspectos da criatividade. Servem, sim, para uma diferenciação de ações criativas e uma maior compreensão de algo multifacetado e repleto de nuances lógico-informacionais. Compreende-se por "Capital- $C$ " aquelas soluções criativas para problemas de extrema dificuldade, geralmente, empreitadas por desenhadores geniais. Define-se por "cursivo-c" todo e qualquer produto criado por indivíduos comuns de uma dada sociedade pois, se a criação é novidade social, também é nova para o indivíduo representante de atividades criativas.

Nossa observação do comportamento criativo e acadêmico de estudantes em cursos de design nos faz crer que não se alcança a priori a fórmula do sucesso, mas que o trabalho, quando atribulado, e o estudo, quando eufórico, ajudam a equilibrar a ansiedade e a reduzir a incerteza sobre as ações criativas dos estudantes. Por mais que se tente chegar diretamente a um produto industrial novo, é necessário associar os tipos de criatividade formulados por lan A. Taylor (1959, p.51-82): Criatividade Expressiva (ações espontâneas, intrínsecas); Criatividade Produtiva (realizações orientadas para objetos/produtos concretos ou abstratos); Criatividade Inventiva (materializações de ideias para novas relações entre coisas e objetos, mas ainda não plenamente realizáveis); Criatividade Inovadora (materializações de ideias para novos produtos, plenamente industrializáveis) e Criatividade Emergentiva (surgimento de novos paradigmas às distintas culturas).

Os tipos de Criatividade não são sequenciados nem compartimentados, mas dispostos lado a lado, e combinados (Quadro 1). A Criatividade Expressiva somada à Produtiva pode guiar à Criatividade Inventiva. Criatividade Produtiva e Inventiva reunidas, podem guiar ao caminho da Criatividade Inovadora. Criatividade Inventiva e Inovadora, quando ajustadas, ajuntadas, em conjunto e em equipe trabalhadas, podem gerar mudanças de paradigmas culturais em cada uma das três áreas de conhecimento -Science, Humanities, Design-, estas ressaltadas por Leonard Bruce Archer, (1922-2005), em The Three Rs (1986, p.55) ou, principalmente, nas três áreas simultaneamente e nos campos de negócios em que essas áreas transitam.

Quadro 1. Relações Evolutivas de Tipos de Criatividade e Reduções de Incertezas

\begin{tabular}{|c|c|c|}
\hline Maior Incerteza Criativa & & \\
\hline \multirow{2}{*}{$\begin{array}{l}\text { Criatividade Expressiva } \\
(+)\end{array}$} & Média Incerteza Criativa & \\
\hline & \multirow{2}{*}{$\begin{array}{l}\text { Criatividade Inventiva } \\
(+)\end{array}$} & \\
\hline Criatividade Produtiva -> & & Menor Incerteza Criativa \\
\hline & Criatividade Inovativa $->$ & Criatividade Emergentiva \\
\hline
\end{tabular}

Fonte: Elaborado pelos autores, com base na pesquisa realizada 
O comportamento profissional do designer é profundamente vinculado à capacidade criadora para alcançar todo tipo de projeto de produto que se desenvolve para novos desenhos industriais, incluídos aqui os produtos para a comunicação gráfico-visual. Desenvolvimento de projeto para sistema de produtos industriais é algo controlado, responsável e dispendioso para os principais projetistas do design, todos os profissionais fecundos, ou seja, arquitetos; engenheiros e desenhadores, ou seja, designers industriais.

Designers industriais estão em pleno processo de retomada de formação em cursos universitários em algumas IES brasileiras. Logo, projetos de produto industrial, mesmo aqueles comissionados para atender a diversos objetivos de comunicação impressa, televisiva, informatizada, devem estar associados, certamente, a uma profissão fecunda, sem perder as características do ofício inventivo, implícito ao design, nem das atividades criativas, como uma das propriedades da Economia e das Indústrias Criativas.

\section{TRABALHO PROJETUAL NAS PROFISSÕES, NOS OFÍCIOS E NAS ATIVIDADES}

Profissões, ofícios e atividades estão carregados de muito trabalho que, por sua vez, é preenchido por atividades processuais e tarefas técnicas. Atividades e tarefas podem ser estafantes, cansativas, fatigantes quando referentes ao labor, ou elegantes, contemplativas, primorosas quando concernentes ao lavor. Isso é o que caracteriza a fórmula do trabalho em Design, seja ele industrial, artesanal ou autoral, a saber: Trabalho em Design $(\tau D)$ é igual a quantidade de labor $(\lambda)$ (esforço, energia) multiplicado pela Qualidade do lavor $(\Lambda)$, tarefa, obra.

\section{$\tau \mathrm{D}=\mathrm{q} \lambda \times \mathrm{Q}^{\Lambda}$}

Domenico De Masi (1938-), sociólogo italiano, em Criatividade e Grupos Criativos (2005), ajuda-nos a caracterizar as atividades criativas, os ofícios inventivos e as profissões fecundas, através da compreensão do termo "trabalho". Este vocábulo, possui dois aspectos: (i) o labor (trabalho fisicamente árduo, repetitivo, operacional) e (ii) o lavor (trabalho emocionalmente intelectual e manualmente extraordinário).

Trabalho remete a muitos conceitos psicológicos, sociológicos e jurídicos; os conceitos de produção, de serviço, atividade, profissão, cargo, tarefa e função, mas também aos de vínculo, contrato, dedicação, paixão, alienação, dever e escravidão. Durante as múltiplas experiências profissionais, cada um de nós tem podido constatar que alguns cargos se chocam com a própria vocação e os próprios gostos. Ainda assim, nós os suportamos, pela necessidade de ganhar dinheiro, de manter a família, de nos realizarmos no tempo livre e assim por diante. Em suma, porque não encontramos nada melhor no mercado. (De MASI, 2005, p.182).

Ainda com referência a De Masi (2005, p.183), o trabalho pode ser instrumental (funcional) ou expressivo (formal). Gravar canções, por exemplo, para um álbum, pode 
ser um simples "trabalho instrumental", realizado por obrigação para atender compromisso contratual, mas não por satisfação. Situação vocacional assim pode, ainda segundo Domenico de Masi, dar origem a uma "alienação destrutiva" (a maioria das bandas rock passaram por isso). Compor melodias e poesias para canções, pode ser "trabalho expressional", e tem tudo para acontecer com satisfação, mesmo que não sejam auferidas recompensas financeiras justas. São tipos de trabalho que melhor indicam a apropriação da vocação e da formação profissional; fazem-nos sentir úteis e realizados, e com a sensação de dever cumprido. Nesses casos, porém, arrisca-se, segundo De Masi, uma "alienação criativa".

Designers industriais, quando imersos em trabalhos expressionais, por causa da alienação criativa, correm o risco de adquirir o que chamaremos aqui de Síndrome de Afastamento Fecundo, i.e., o alheamento da criatividade orientada, da "criatividade planejada", como diria Bruce Archer na década de 1970, distinta da criatividade livre, espontânea, incidental.

\section{CONSIDERAÇÕES FINAIS}

Para completar este artigo, tecemos considerações sobre as diferenças nos movimentos e nas motivações de atividades criativas, ofícios inventivos e profissões fecundas. As três ocupações podem ser esquematicamente representadas pelo caminhar "mede-palmos" de um anelídeo, pelo ziguezague do registro gráfico do pulsar do coração, e pelo deslocar helicoidal, orientado e direcional de espermatozoides. (Figura 1).

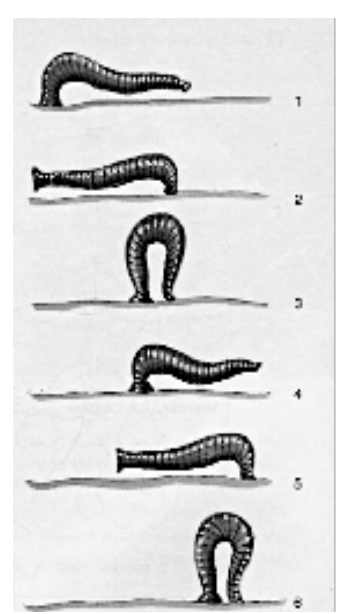

(a)

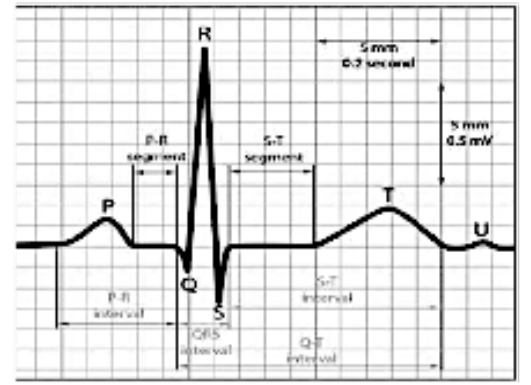

(b)

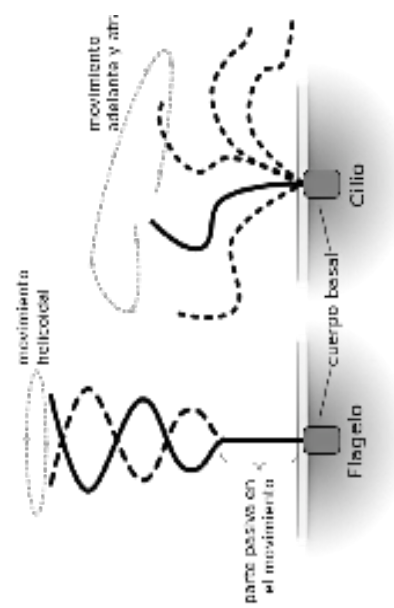

(c)

Figura 1 - (a) movimento "mede-palmos" nas atividades criativas; (b) movimento "sístole-diástole" dos ofícios inventivos; (c) movimento orientado e direcional das profissões fecundas. Fonte: imagens meramente ilustrativas, obtidas na rede mundial de computadores.

Nas atividades criativas o indivíduo faz uso de recursos inerentes relacionados com a sua capacidade intelectual e criativa e suas habilidades manuais construtivas, modelativas, plasmativas. O movimento "mede-palmos" nessas atividades representa a busca por situações profissionais mais satisfatórias e é um movimento de risco pois depende de variáveis externas, muitas vezes incontroláveis como por exemplo o momento econômico e a apreciação do trabalho pelo público. $O$ indivíduo pode experimentar trabalhar numa loja de bicicleta, depois ser taxista e então se apaixonar 
pela culinária tornando-se um chef de sucesso (Figura 2). Nos ofícios inventivos, o indivíduo está carregado de euforia e angústia pois sente estar próximo da descoberta de algo original mas tem dúvidas sobre como tornar públicas as suas ideias. 0 aprimoramento da ideia inicial geralmente requer a obtenção de suporte técnico e de apoio financeiro para viabilização e comercialização.

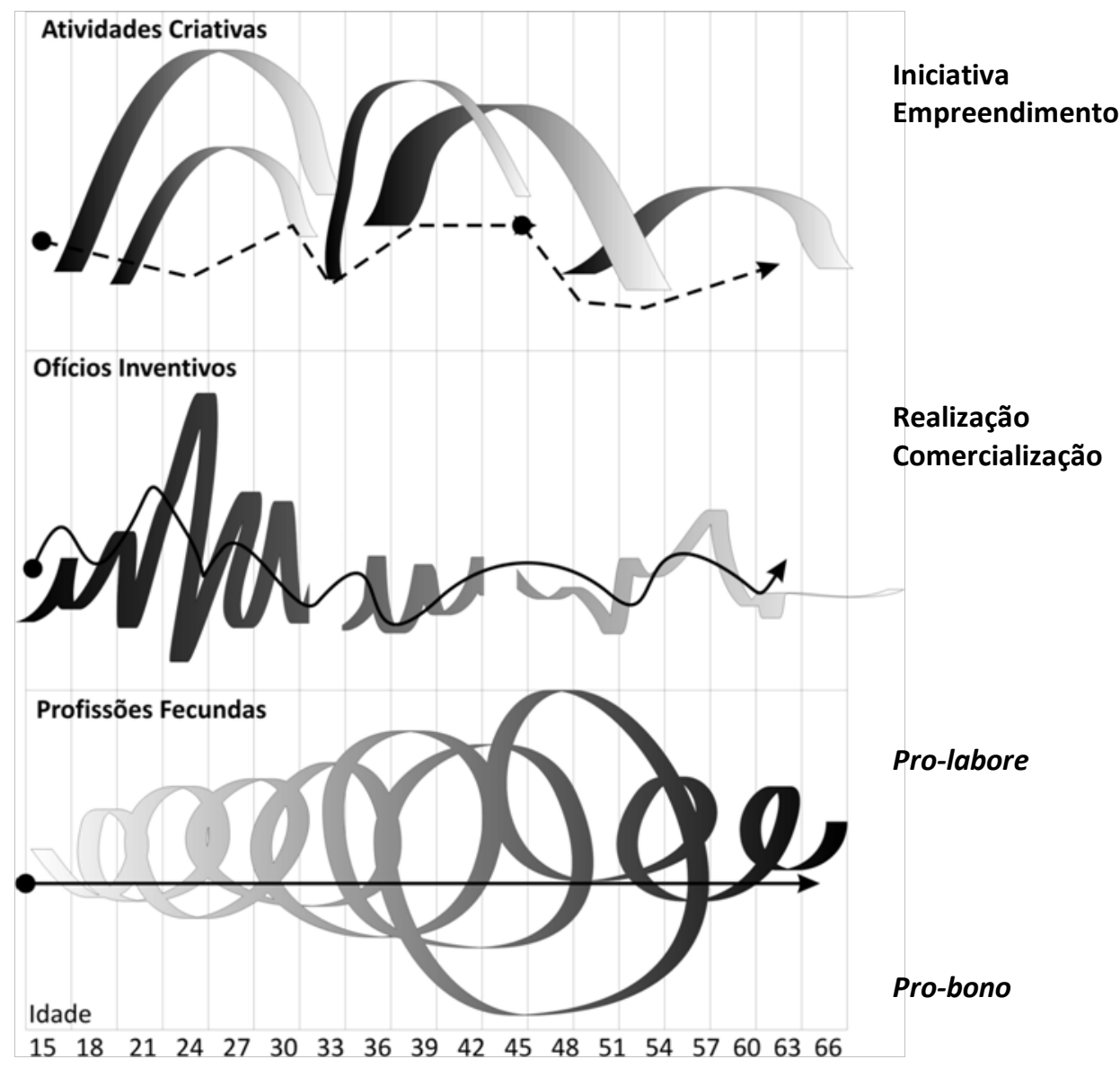

Figura 2 - Nas atividades criativas o indivíduo faz uso de recurso próprio inerente: iniciativa; nos ofícios inventivos, o indivíduo pode ter ideias geniais, altamente lucrativas, quando ainda jovem; nas profissões fecundas, profissionais se desenvolvem por meio de conhecimento cumulativo que pode ter seu desempenho valorizado até bem mais dos 66 anos.

Fonte: Elaborado pelos autores.

Como a ideia genial pode acontecer quando o indivíduo é ainda muito jovem e inexperiente, as etapas " 1 . Proteja sua invenção; 2 . Aprenda tudo sobre sistema de patentes; 3 . Seja realista sobre o custo de patentes; 4 . Venda você mesmo a sua invenção; 5. Encontre um industrialista" são geradoras da angústia. Mas, uma vez identificado esse padrão de trabalho, o movimento "sístole-diástole" garante a continuidade e longevidade à sua atuação. Thomas Edison, depois de estabelecido como inventor, propôs-se a meta de produzir uma nova invenção a cada dez dias.

O movimento helicoidal, orientado e direcional das profissões fecundas permite que maturidade e conhecimento cumulativo valorizem o desempenho do indivíduo. Dependendo da base de conhecimentos desse indivíduo, a poupança intelectual e criativa formada será renovada a cada experiência. A base do conhecimento pode ser acionada sempre que um problema novo surgir em qualquer setor projetual. 
Mesmo não havendo consenso na própria comunidade de designers sobre a conveniência de uma regulamentação profissional, os estudantes podem transformar sua carreira numa profissão fecunda, sem renunciar às oportunidades de trabalho que surgirem em ofícios inventivos ou em atividades criativas.

\section{REFERÊNCIAS}

ARCHER, B. Design Awareness and Planned Crativity in Industry. London: Design Council, 1974.

BONSIEPE, Gui. Desenvolvimento pelo Design. In PATROCÍNIO, G.; NUNES, J. M. (Org.). Design e Desenvolvimento 40 Anos Depois. São Paulo: Blucher, 2015, p.229-250.

BRASIL, Diário Oficial de União, 28 out. 2015.

CROSS, Nigel et al. Diseñando el Futuro. Barcelona: Gustavo Gili, 1980.

DE MASI, Domenico. Fantasia e concretude. Rio de Janeiro: Sextante, 2005.

FELDMAN, D. H. The creation of multiple intelligence theory. In: SAWYER, Robert K. et al. Creativity and development. New Your: Oxford University Press, 2003, p. 139-185.

GLADWELL, Malcolm. Fora de Série: Outliers. Rio de Janeiro: Sextante, 2008.

GOSLLET, Dorothy. The Professional Practice do Design. 2nd edition. London: BT Batsford, 1978.

INDUSTRIAL DESIGNERS SOCIETY OF AMERICA disponível em http://www.idsa.org KAUFMAN, J. C.; BEGHETTO, R. A. Beyond Big and Little. Review of General Psychology, 13 (1), p 1-12.

PHILIPPI, Simone (Editor). Starck. Köln: Taschen, 1996.

SAWYER, Robert K. Explaining Creativity. Oxford: Oxford University Press, 2012.

TAYLOR, Ian. The Nature of Creative Process. In SMITH, P. (Ed.). Creativity: An

Examination of the Creative Process. New York: Hasting House, 1959, p.51-82.

ULRICH, Karl; EPPINGER, Steven. Product Design and Development. Boston: Irwin; McGraw-Hill, 2000. 